servative management. Admittedly, you conclude your article with a reminder of the need for a controlled trial, but much of the conviction and finality of this message is unfortunately removed by your having preceded it with such an aggressive phrase as "striking success", which must surely have left the more permanent imprint on the mind of the uninvolved reader.

While there is little doubt about the value of $c$ clophosphamide in the steroid-dependent nephrotic child, its effect in other forms of glomerulonephritis is not proved and requires evaluation in controlled therapeutic trials. Meanwhile, it should only be used after very carefully weighing its known immediate toxicity and its uncertain long-term effects on immature gonads against the individual child's prognosis. The treatment is easy but it is the assessment of prognosis which may present the greater difficulty, even to skilled and experienced physicians.I am, etc.,

Children's Hospital,

R. H. R. WHITE

Birmingham

\section{Haemorrhage Mimicking Intravascular Haemolysis}

SIR,-I have seen two patients with a ruptured ectopic pregnancy mimicking intravascular haemolysis. The presentation and laboratory findings were similar in both cases and the second one only is briefly described.

She was a 28-year-old English woman who had a bloodstained vaginal discharge and mild hypogastric pain, which had started one week before her expected period and lasted for 23 days until admission. Seven days before admission she also had an episode of severe abdominal pain with sweating lasting a few hours. During the two weeks before admission, she had attended the V.D. Clinic and was treated as a possible case of salpingitis with tetracycline. Serological tests and cultures were negative. On her last visit to this clinic she was noted to be pale and tired and was referred for a blood count.

She was admitted as an emergency when her haemoglobin was found to be $7.4 \mathrm{~g} /$ $100 \mathrm{ml}$ with $9.2 \%$ reticulocytes and the plasma was noted to be brown with a strongly positive Schumm's test. Her urine had been dark for about a week. She was pale, but neither looked nor felt ill. Her pulse and blood pressure were normal and the abdomen soft and without tenderness. Investigations on admission were negative for G-6-PD deficiency, autoantibodies including Donath-Landsteiner antibody, paroxymal nocturnal haemoglobinuria, and Heinz bodies. Blood cultures yielded no growth; the white cells and platelets counts and the blood urea were normal. The urine showed excess urobilinogen and haemosiderin granules, demonstrated by Perl staining of the deposit. Serum lactic dehydrogenase was markedly raised at 1100 units, alanine transaminase raised to 60 units, and aspartate transaminase raised to 43 units.

As the history was reminiscent of the first case a gynaecologist's opinion was sought. He made a clinical diagnosis of ruptured ectopic pregnancy, which was confirmed at operation. A sample of the $750 \mathrm{ml}$ of blood found in the peritoneal cavity had a P.C.V. of $80^{\circ} \prime$ and the serum was dark brown with a strong red tinge. It was as umed that reabsorption into the circulation of this lysed old blood over 8 days or more was responsible for the heavy methaemalbuminaemia, haemosiderinuria and the very high serum lactic dehydrogenase level. The patient made an uneventful recovery and the methaemalbuminaemia disappeared over the next four days.

I feel these cases are worth reporting as both were initially thought to have anaemia due to intravascular haemolysis rather than haemorrhage. Severe abdominal pain and shock can occur during episodes of acute haemolysis and some standard medical and haematological text books do not mention reabsorption of lysed blood as a cause of methaemalbuminaemia and haemosiderinuria. Cecil and Loeb" states that "its occurence [methaemalbuminaemia] is pathognomonic for intravascular hemolysis even in the absence of free hemoglobin in the plasma or urine." Reference to methaemal buminaemia following extravasation of large amounts of blood into epithelial-lined spaces was found in Cantarow and Trumper's Clinical Biochemistry ${ }^{2}$ and it has been described following reabsorption of massive deep haematomata.-I am, etc.,

JEANNE D. REEve

Hacmatology Department,

Prince of Wales's General Hospital,

London N.15

1 Ham, T. H., in Cecil and Loeb Textbook of Medicine, ed. P. B. Beeson and W McDermott 2 12th edn., p. 1049. Philadelphia, Saunders. 1967. Cantarow, A., and Trumper, M., Clinical

\section{Diverticular Disease of the Colon}

SIR,-In view of the extreme rarity of diverticular disease of the colon in Africans, as discussed by $\mathrm{Mr}$. N. S. Painter and $\mathrm{Mr}$. D. P. Burkitt in their article last week (22 May, p. 450), I should like to report a case of diverticulitis occurring in Malawi.

The patient, a Bantu woman of around 40 years of age, was sent to Zomba General Hospital in August 1970 from a rural dispensary with a history of severe lower abdominal pain of two days' duration. A tentative diagnosis of ruptured ectopic pregnancy had been made.

When I first saw her, she was thin, dehydrated and shocked with marked tenderness and guarding over the lower abdomen, absent bowel sounds, and tenderness in the pouch of Douglas. After resuscitating her with intravenous fluids and blood, laparotomy was performed.

The findings were of faecal peritonitis, with the loops of the intestine matted together and covered with a greenish exudate. Multiple diverticula were found on the large bri...1, two of which on the transverse colon had perforated giving rise to the peritonitis. The appendix was normal. The perforations were closed, caecostomy performed, and a drain inserted, but, despite blood transfusion, intravenous fluids, and high doses of antibiotics, the patient died five days after operation.

This was the only case of diverticulitis I saw in two and a half years as a medical officer in Malawi. However, since the only routine examination carried out on patients with symptoms referable to the large bowe was microscopic examination of the stool and barium enemas were only rarely performed, it is possible that cases of diverticular disease were missed. In addition, very few postmortems were carried out for other than medicolegal reasons and so, little information is avail able from that source.-I am, etc.,

Western Infirmary,

John F. Calder

Glasgow W.1

\section{Token Therapy}

SIR,-I was interested to read the article by Dr. I. M. Marks and others on "Operant Therapy for an Abnormal Personality" (20 March, p. 647).

We had a similar case of a hysterical psychopathic female aged 20 , whose behaviour was characterized by impulsive, unpredictable, destructive outbursts against property or herself. All forms of medication and supportive treatment had been tried but her calm periods never lasted longer than a few days. Eventually we tried a system of giving her so many tokens for each half-day of good behaviour; a certain number of tokens thus earning her more freedom and a chance to return from the closed ward to the admission ward. Her behaviour improved considerably for some three months, until we got to the stage where we tried to find her suitable work. Unfortunately, the two jobs she tried failed to provide the right milieu for this patient and therapy was brought to a sudden end by her incarceration in prison, following an outburst of anti-social behaviour in the town.

Although the outcome in this case was not successful, there is no doubt in my mind that token therapy has an important part to play in treating this sort of case where immediate tangible rewards can satisfy such immature personalities.-I am, etc.,

\section{J. C. M. WILKINSON}

Pastures Hospital,

\section{Silicone for Osteoarthritic Joints}

SIR, - I was astonished by the high incidence of reactions to intra-articular silicone in the small series reported by Professor V. Wright and others (15 May, p. 370). This was not the experience of Corbett et al. ${ }^{1}$ nor indeed my own." A relevant factor may be that in both these studies the silicone was obtained from a different source and, incidentally, was of a different viscosity. No fewer than three out of the 20 patients in the present report had reaction to their silicone injections. This, I feel, throws suspicion on the material used and so on the results obtained.

As I have said previously, ${ }^{3}$ a lubricant is unlikely to be effective where there is gross bony incongruity such as in advanced osteoarthrosis, except where the disease is mainly patello-femoral, when it can help by floating the patella off the femoral condyles. The main indication for its use is in dry rheumatoid joints where a bony contour is often maintained.

In normal joints moving slowly under load viscosities can rise to 10,000 centipoise; in the presence of rough surfaces, logically, a much higher viscosity is needed. We are at present using a silicone of 100,000 centistoke viscosity and this seems to be acting more effectively and is also retained in the joints for a much longer period.

I am surprised by the observation that in 
Leeds mere admission to hospital improves joint stiffness-perhaps because as a clinician I do not judge joint stiffness by the amount of "loose torque."-I am, etc.,

B. Helal

London W.1

1 Corbett, M., Seifert, M. H., Hacking, C., and Webb. S., British Medical 尹ournal, 1970, $1,24$. Helal, B., and Karadi, B. S., Annals of Physical Medicine, 1968, 9, 334 .

Papers read on Artificial Lubrication at Hôpital de la Pitié, Paris, February 1970, Hospital for Gordon Research Conference, Andover, U.S. A. June 1970.

\section{Price of Treatment}

SIR,--I wonder whether the cost of the care of children with meningomyelocele (15 May, p. 385) is or should be an argument of major weight in the discussion of plans for care of such people.

What is the cost of treating largely selfinflicted disorders such as cancer of the lung and obesity? And the operations on cancer of the lung are, I believe, unavailing in something like 9 out of 10 cases, and the results of treatment of obesity perhaps to be considered unrewarding in terms of time and money consumed.

I have set out elsewhere arguments that money does not suitably enter this discussion. ${ }^{1}$ The argument on this topic is not yet solved, but we need to look at many other factors before deciding, as Mr. C. D. R. Lightowler does, that early closure of meningomyelocele should not be encouraged. If his conclusions had proposed selection of children to have early closure and he had given criteria, his contribution to the discussion would have been more helpful-I am, etc.,

\section{Guy's Hospital, \\ 1 Mac Keith, R. C., Maternal and Child Care, 1967, 3, 437}

\section{Hypercapnia}

SIR,-The Greeks may have had a word for it, but it was none of those misprinted in Dr. R. J. Lewis's short and reasoned letter (22 May, p. 471). They certainly had a word meaning to miss the mark. To find three verbal hamartomata disfiguring the British Medical fournal makes one wonder whether Snow was not perhaps right, after all, about two cultures.-I am, etc.,

\section{Donald EMSLIE-SMith} Department of Medicine

University of Dundee,

Dundee

** We regret the misprints in Dr. Lewis's letter-and the omission of an aspirateED., B.M.f.

\section{Care of Chronic Psychotics}

SIR,-What a relief to see expressed in your columns a realistic view of the needs of asylum vested in established mental hospitals (15 May, p. 351).

Unfortunately since 1961 a great deal of nonsense, though sincere nonsense, has ordered official policy first adumbrated by Mr. Enoch Powell in his famous "Water Tower" speech to the National Council of Mental Hygiene (now the National Associa- tion for Mental Health). On that occasion many experienced administrators viewed with grave concern a Minister of Health seeming to make an irresponsible attack on mental hospitals and some of them, myself included, expressed their disagreement.

A principal malaise of English psychiatry has been and remains a dearth of stable leadership in the matter of the care of the chronic psychotic owing to our leaders either lacking sound experience in such matters or having rejected the role of alienist, which too often they affect to despise and too frequently deride. They have been so busy, either assimilating a bewildering assortment of dynamic theories deriving from Freud or pursuing an interest in physical remedies acting on the central nervous system that the citadel of psychiatry has been deserted.

Were they to have inspired those whom they teach to bear in mind constantly their responsibility to society as well as to their patients and fuse their vision of these two images the sorry state of affairs to which your leading article draws long overdue attention might not have occurred.-I am etc.,

Harpenden,

Harold Palmer

\section{What Price Fellowship?}

SIR,-I regret that Drs. N. Rosen and R. C. Sanders (22 May, p. 467) should take exception to our invitation to American physicians to join the Royal Society of Health. While they are fully entitled to their views, I feel that they are under some misapprehension regarding the nature and purpose of the Society.

The Society is not a professional institute, but a voluntary non-profit organization and a registered charity, bringing together in appropriate grades of membership, the highest of which is the Fellowship, all who wish to support it in its work of promoting the health of the people all over the world. Its journal has world wide recognition, and the annual health congress and the biannual international health conference are well known.

I would also like to mention that many favourable letters concerning our invitation have been received from members of the medical profession in the United States. Not only have a substantial number of these physicians joined, but they have taken the trouble to write and express their pleasure and appreciation in having been given the

\section{Prescribing on Clinical Grounds}

SIR,-One of the most jealously guarded rights of doctors working in the National Health Service is their freedom to prescribe any drug their patient needs on clinical grounds alone. Any interference with this right to prescribe is deeply resented, and the recent discussions on the cost-related prescription charges have shown the whole profession to be united against them.

It is with some trepidation, therefore, that I challenge the reality of the fundamental rights to prescribe based on clinical grounds alone. Before the N.H.S. existed patients were treated privately and paid the full price of their drugs. Doctors were extremely conscious that their choice of treatment must opportunity to do so. Your correspondents may also be interested to know that a leading American health society has issued similar invitations to the Society's members so as to further its own membership in the United Kingdom.-I am, etc.

A. B. STEWART Chairman of Council of the Society,
Royal Society of Health

L.undon S.W.1

\section{Cholera in Bengal}

SiR,--Following reports of a major outbreak of cholera, a number of members have been contacting the Association in order to offer their services or financial help.

Under a long-standing arrangement the British Medical Association has channelled arrangements for medical volunteers through the British Red Cross Society which maintains a central register. Application forms may be obtained from the Commonwealth Medical Advisory Bureau at B.M.A. House. At the time of writing, no requests for medical personnel have been received.

I understand that donations may be made to: The India/Pakistan Relief Fund, P.O. Box 999, London W.C.2R OSD. -I am, etc.,

Alan Gilmour Commonwealth Mcdical Advisory Bureau, B.M.A. House,

\section{Multiple Eponyms}

SIR,-A glance at the list of eponyms in the Nomenclature of Disease ${ }^{1}$ does not reveal any disease named after more than three observers. I have heard of the LaurenceMoon-Bardet-Biedl syndrome, ${ }^{2}$ but recently I had the pleasure to read a paper about a disease named after no fewer than five observers. It is entitled "Werdnig-HoffmannWohlfart - Kugelberg - Welander Disease : Nosological Unity and Clinical Variability in Intrafamilial Cases."

Is this a record? - I am, etc.

Royal Infirmary,

T. J. DAvid

Royal College of Physicians of Lnndon. Nomenclature of Disease 8th edn. London, H.M.S.O.

2 Blumei, J., and Kniker, W. T. Texas Reports on Biology and Medicine, 1959, 17, 391. 3 Ghetti, B., et al., Acra Geneticae Medicae et

be influenced by the ability of their patient to afford the cost.

Private practice still exists in Britain today and is by no means confined to the affluent. Modern private doctors who are able to choose from a wide range of powerful and effective drugs are equally cost-conscious in order to lessen the burden on their patients who pay, not just a nominal prescription charge, but the full market price for their drugs.

The private doctor thus cannot prescribe on clinical grounds alone; he must temper his judgement with hard economic facts. $\mathrm{He}$ has the compensation of knowing that the most expensive drugs are rarely effective; if 